\title{
Serum Cortisol Seems To Be a More Appropriate Marker for Adrenocortical Reserve Evaluation in ACTH Test in Comparison to Salivary Cortisol
}

\author{
M. KOSÁK ${ }^{1}$, V. HÁNA ${ }^{1}$, M. HILL ${ }^{2}$, K. ŠIMŮNKOVÁ ${ }^{1,2}$, Z. LACINOVÁ ${ }^{1}$, M. KRŠEK ${ }^{1}$, \\ J. MAREK ${ }^{1}$
}

${ }^{1}$ Third Department of Medicine, General University Hospital and First Faculty of Medicine, Charles University, Prague, Czech Republic, ${ }^{2}$ Institute of Endocrinology, Prague, Czech Republic

Received July 12, 2013

Accepted November 1, 2013

On-line January 8, 2014

\begin{abstract}
Summary
Salivary cortisol reflects the free fraction of serum cortisol. Monitoring salivary cortisol may be a promising alternative method for assessing serum cortisol in some clinical situations. We aimed to compare the reliability of salivary vs. serum cortisol during ACTH test. 84 subjects (mean age 63.2; 24-89 years; $\mathrm{n}=66$ males) suspected for adrenocortical insufficiency underwent an ACTH test. Patients were divided based on peak serum cortisol into hypocortical group with cortisol $<500 \mathrm{nmol} / \mathrm{l}$ and to reference group cortisol $>500 \mathrm{nmol} / \mathrm{l}$. Median serum cortisol levels in reference group were 445, 766, and $902 \mathrm{nmol} / \mathrm{l}$ at 0,30 , and 60 minutes, respectively, and in hypocortical group were 256, 394, and $453 \mathrm{nmol} / \mathrm{l}$. Median salivary cortisol levels were $19.02,40.02$, and $62.1 \mathrm{nmol} / \mathrm{l}$ in reference group, and 9.60, 14.08 , and $13.28 \mathrm{nmol} / \mathrm{l}$ in hypocortical group. Obtained values showed good correlation between serum and salivary cortisol $(p<0.0001)$. The percentage of explained variability $R^{2}$ (coefficient of determination for linear model) representing a measure of agreement between experimental values and predictions for repeated measures ANOVA, was significantly higher $(p=0.021)$ for serum cortisol $\left(R^{2}=93.4 \%\right)$ when compared to the salivary cortisol $\left(R^{2}=89.3 \%\right)$. A stronger discriminating power of serum versus salivary cortisol suggests that it seems to be slightly, but statistically significantly more appropriate marker of adrenocortical reserve in ACTH test.
\end{abstract}

\section{Key words}

Hypocorticalism • ACTH test • Serum cortisol • Salivary cortisol

\section{Corresponding author}

M. Kosák, Third Department of Medicine, General University Hospital and First Faculty of Medicine, Charles University, U nemocnice 1, 12808 Prague 2, Czech Republic. E-mail: mikulas.kosak@gmail.com

\section{Introduction}

The ACTH stimulation test and serum cortisol levels are well-established indicators used to assess adrenocortical reserve in patients suspected of having primary adrenal insufficiency, or hypotalamo-pituitaryadrenal (HPA) axis dysfunction. (Hurel et al. 1996, Agha et al. 2006). The ACTH test is broadly used for initial screening purposes and is relatively easy to perform. Different stimulation tests are available. The most important of these tests are the insulin tolerance test (ITT), metyrapone test, ACTH test and the CRH test. All of these tests have their limitations. Although ITT is still considered to be a "gold standard" for testing HPA axis function, its main contraindications are neurological and cardiovascular and it should also not be used in elderly patients. For these reasons the ITT has largely been replaced by the ACTH test in clinical practice in recent years.

A variety of conditions may alter serum cortisol levels and reduce the applicability of the HPA axis testing regardless of the stimulation test used. Cortisol binding globulin (CBG, transcortin) levels have been shown to affect total serum cortisol level and reduce its reliability 
as a marker of adrenocortical function (Šimůnková et al. 2008, Perogamvros et al. 2010b). Besides inherited deficiencies, the most common reasons for changes in CBG levels are estrogen therapy (oral contraceptives or hormone replacement therapy) and pregnancy (Šimůnková et al. 2008, Perogamvros et al. 2010b).

Clinical situations, particularly critical illness such as sepsis, liver cirrhosis or nephrotic syndrome, may decrease synthesis and/or increase CBG clearance. In these cases, measuring total serum cortisol is an inappropriate method to assess cortisol deficiency or hyper-secretion (Hamrahian et al. 2004, Arafah 2006). As a result, there is a need to identify a more sensitive indicator to assess adrenocortical reserve in these situations.

To date, many articles have been published suggesting the superiority of cortisol free fraction assessment in these clinical conditions (Hamrahian et al. 2004, Šimůnková et al. 2008). Free fraction serum cortisol represents about $5 \%$ of total cortisol (Limor et al. 2011). Measurement of free serum cortisol by equilibrium dialysis cannot be routinely used due to methodological limitations (technical demands and time). The free cortisol fraction can be estimated using a mathematical model based on serum cortisol levels (free cortisol index).

Measuring urinary free cortisol may be an alternative approach. This method is often used to diagnose cortisol hypersecretion conditions, but it is not suitable for assessing hypocorticalism. Salivary cortisol reflects the free portion of cortisol (Gozansky et al. 2005). Measurement of salivary, rather than serum, cortisol could prove advantageous, given that saliva samples are easy to collect, non-invasive and well tolerated by patients. Furthermore, the stressful event of collecting a blood sample is also avoided (Meeran et al. 1993). For this reason, the measurement of salivary cortisol has become a popular technique used in psychiatric and psychological research.

We have compared the variability of observed results of both analytes and evaluated their realiability using statistical methods.

\section{Subjects and Methods}

\section{Subjects}

84 subjects were analyzed in our study with mean age 63.2 (24-89 years, 66 men). The group consisted of patients with possible hypocorticalism due to various clinical conditions. All patients underwent an ACTH test. The indications for the test are listed in the Table 1.

Table 1. Diagnoses and clinical conditions leading to indication of the ACTH test in patients involved in the study.

\section{Reference group}

$\begin{array}{lc}\text { Diagnosis } & \text { No. of patients } \\ \text { Traumatic brain injury } & 76\end{array}$

\section{Hypocortical group}

\begin{tabular}{lc} 
Diagnosis & No. of patients \\
Bilateral lymphoma of the adrenal & 1 \\
gland & \\
Traumatic brain injury & 2 \\
Addison's disease due to & 1 \\
autoimmune adrenalitis & \\
Pituitary surgery & 4 \\
\hline
\end{tabular}

Patients were divided into one of two groups based on peak serum cortisol concentrations during the ACTH test. A peak serum cortisol of more than $500 \mathrm{nmo} / \mathrm{l}$ was considered normal adrenocortical function. These patients formed the reference group ( $n=76$, mean age 64 years, range 24-89 years, 60 men). Patients with a peak serum cortisol below $500 \mathrm{nmol} / \mathrm{l}$ were included in the hypocortical group $(n=8$, mean age 61.4 years, range 49-77 years, 6 men). Pregnant women, patients taking oral contraceptives, corticosteroids or any interfering medication, and those with co-morbidities that might alter cortisol binding globulin levels were excluded from the study.

The study protocol was approved by the Local Ethical Committee and all participants signed informed consents.

\section{Testing procedures}

The test was performed in the morning hours (between 0800 and 0900) and patients were instructed not to smoke, eat, drink or brush their teeth $60 \mathrm{~min}$ before the test. At the beginning of the test, an intravenous cannula was inserted in the antecubital vein $30 \mathrm{~min}$ before the first sample was performed. Following an overnight fast, basal blood and saliva samples were obtained (time 0). Saliva samples were collected into Salivette tubes (Sarstedt, Nümbrecht, Germany). Patients were instructed 
to drool into the collection tube. After the first sample of blood and saliva were collected, $250 \mu \mathrm{g}$ of synthetic human 31-24 ACTH (Synacthen, Novartis, Basel, Switzerland) was administered intravenously. Saliva and blood samples were taken again, after 30 and $60 \mathrm{~min}$ following the same procedures.

\section{Laboratory methods}

Serum cortisol levels were measured by commercial RIA kit (Immunotech, Marseille, France). Sensitivity was $10 \mathrm{nmol} / \mathrm{l}$. The intra- and inter-assay variability of all kits was less than $5.0 \%$ and $10.0 \%$, respectively.

Salivary cortisol concentrations were determined by commercial competitive immunoenzymatic colorimetric method according to the manufacturer's instructions (DiaMetra, Milano, Italy). Sensitivity was $0.14 \mathrm{nmol} / \mathrm{l}$. The intra- and inter-assay variability of all kits was less than $5.0 \%$ and $10.0 \%$, respectively.

\section{Statistical analysis}

The data were evaluated using repeated measures ANOVA model consisting of subject factor, between-subject factor Status (hypocortical vs. reference group), within-subject factor Time $(0,30$, and $60 \mathrm{~min})$ and Status $\times$ Time interaction. Due to skewed data distribution and non-constant variance, the original data were transformed by a Box-Cox transformation to attain symmetry and homoscedasticity for ANOVA testing (Meloun et al. 2000). For a graphical demonstration, the transformed means and $95 \%$ confidence intervals were re-transformed into the original scale. The homogeneity of the transformed data was tested as described elsewhere (Meloun et al. 2004). Least significant difference multiple comparisons followed the ANOVA testing. Sensitivity, specificity and their confidence intervals were calculated with the Wilson score method as described elsewhere (Armitage and Berry 1994).

\section{Results}

Simultaneously we assessed serum and salivary cortisol levels in patients with normal HPA axis function and those with hypocorticalism.

Serum cortisol results were expressed as medians (lower and upper quartiles). Reference group had median cortisol levels of 445 (372,558), 766 (677, $877)$ and $902(771,1060) \mathrm{nmol} / \mathrm{l}$ at 0,30 and 60 minutes, respectively. Serum cortisol levels were in the hypocortical group: 256 (177, 290), 394 (336, 457) and $453(401,476) \mathrm{nmol} / 1$ at 0,30 and 60 minutes, respectively.

Median salivary cortisol levels (lower - upper quartile) in reference group were 19.02 (15.73, 27.60), $40.02(33.95,52.99)$ and $62.1(48.30,75.35) \mathrm{nmol} / 1$ at 0 , 30 and 60 minutes, respectively. Salivary cortisol levels were much lower in the hypocortical group: 9.60 (3.81, 17.72), 14.08 (8.80, 19.40) and 13.28 (11.79, 21.14) $\mathrm{nmol} / \mathrm{l}$ at 0,30 and 60 minutes (Table 2$)$.

Table 2. The basal and ACTH stimulated serum and salivary cortisol levels (both in nmol/l) expressed as median with quartiles.

\begin{tabular}{|c|c|c|c|c|}
\hline & & 0 min & $\begin{array}{l}\text { Time } \\
30 \text { min }\end{array}$ & $60 \mathrm{~min}$ \\
\hline \multirow[b]{2}{*}{ Serum } & Reference & $445(372,558)$ & $766(677,877)$ & $902(771,1060)$ \\
\hline & Hypocortical & $256(177,290)$ & $394(336,457)$ & $453(401,476)$ \\
\hline \multirow{2}{*}{ Saliva } & Reference & $19.02(15.73,27.60)$ & $40.02(33.95,52.99)$ & $62.1(48.30,75.35)$ \\
\hline & Hypocortical & $9.60(3.81,17.72)$ & $14.08(8.80,19.40)$ & $13.28(11.79,21.14)$ \\
\hline
\end{tabular}

Peak serum cortisol was observed at 60 minute after the ACTH administration in all subjects, with the exception of one performed test. Similarly, peak values of cortisol were observed in saliva at 60 minute in all, but 9 subjects (6 of these tests were in the reference group and 3 tests in the hypocortical group). We found a significant correlation between serum and salivary cortisol levels $\mathrm{r}=0.773, \mathrm{n}=272, \mathrm{p}<0.0001$, within individuals (Fig. 1 and 2).

We attempted to estimate normal values based on the data observed in our cohort of individuals with normal response in serum cortisol. In the reference group were values of salivary cortisol as follows (expressed as intervals in which $95 \%$ of subjects should occur): 
13.19-32.23 at minute $0,27.9-61.13$ at minute 30 and 43.09-89.09 $\mathrm{nmol} / 1$ at minute 60 . Calculated sensitivity and specificity of salivary cortisol was 0.5 and 0.895 for minute $0,0.857$ and 0.866 for minute 30 and 1 and 0.817 for minute 60 , respectively.

The most important factor for serum cortisol was represented by the Status $(\mathrm{F}=473.4)$, followed by Time $(\mathrm{F}=116.9)$ and the Status $\times$ Time interaction $(\mathrm{F}=19.4)$ (indicating a different shape of the time profile for hypocortical patients and reference group) and the subject factor $(\mathrm{F}=8.35)$ (separating inter-individual variability).

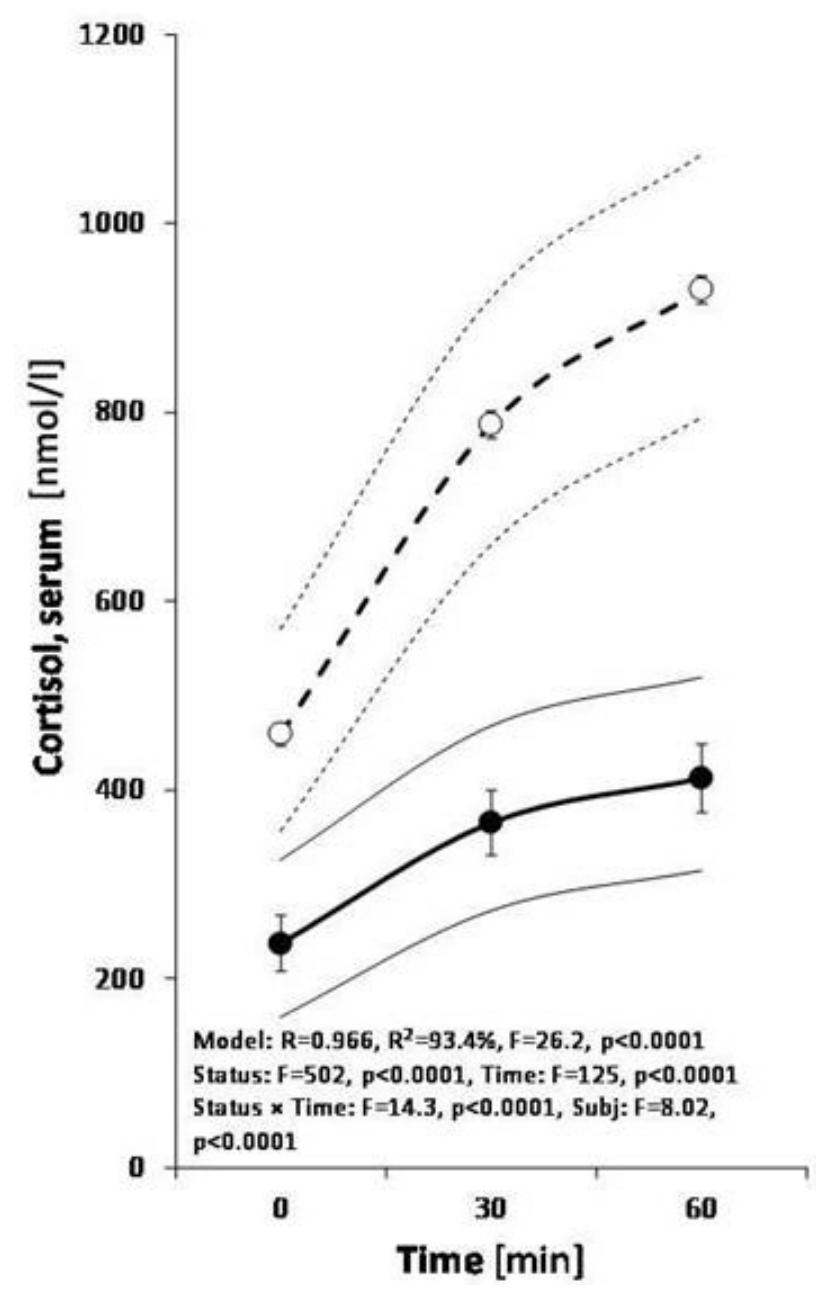

Fig. 1. Different profiles of serum cortisol for 250 ug ACTH test between hypocortical patients and reference group as evaluated using repeated measures ANOVA model (for details see Statistical analysis). The empty and full circles with error bars represent group means with their $95 \%$ confidence intervals for reference and hypocortical group, respectively. The dashed and full thin curves symbolize the assessed $2.5 \%$ and $97.5 \%$ percentile for reference and hypocortical group, respectively. $R, R^{2}, F$, and $p$ represent the correlation coefficient of the ANOVA model, percent of variability explained by the repeated measures ANOVA model, F-ratio, and level of statistical significance, respectively.
The percentage of explained variability $\mathrm{R}^{2}$ (coefficient of determination for linear model) representing a measure of agreement between experimental values and predictions for repeated measures ANOVA model, was significantly higher $(p=0.021)$ for serum cortisol $\left(\mathrm{R}^{2}=93.4 \%\right)$ when compared to the salivary cortisol $\left(\mathrm{R}^{2}=89.3 \%\right)$. In terms of statistical reliability, our findings provide evidence that serum cortisol is a slightly, but statistically significantly better parameter than salivary cortisol (expressed by the variability) for assessing adrenocortical reserve by ACTH test.

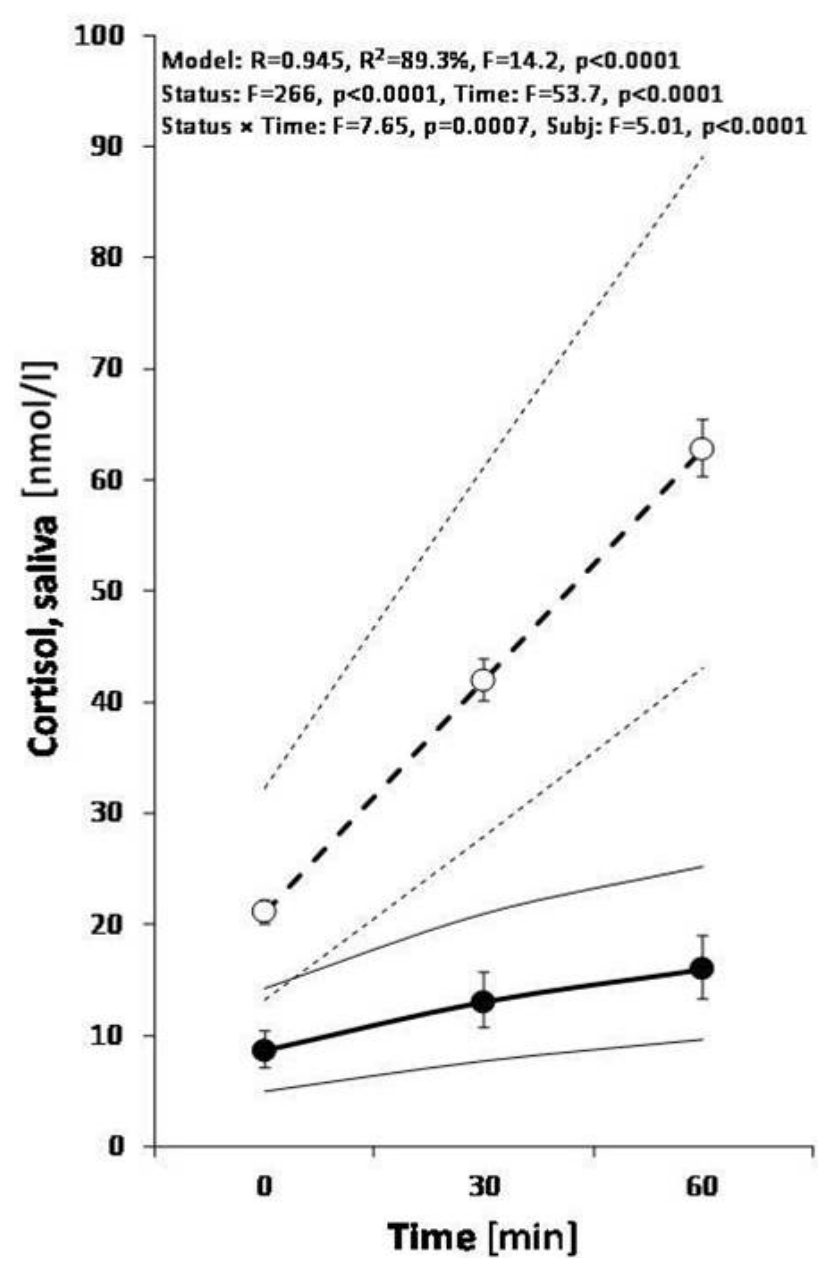

Fig. 2. Different profiles of salivary cortisol for 250 ug ACTH test between reference group and hypocortical patients as evaluated using repeated measures ANOVA model (for details see Statistical analysis). The drawings and symbols are the same as for Figure 1.

\section{Discussion}

Salivary hormone levels have been used for diagnostic purposes since the early 1980s, specifically in the diagnosis of Cushing's syndrome (Riad-Fahmy et al. 
1980). Late-night salivary cortisol levels have high sensitivity (92\%) and specificity (96\%) in diagnosis of Cushing's syndrome (Raff 2009). In contrast, there is decreased sensitivity and specificity of this indicator, when used to assess subclinical Cushing's syndrome (Masserini et al. 2009). As a result, there is still some controversy regarding the use of salivary hormone levels more broadly for diagnostic purposes.

The reliability of using salivary cortisol as a diagnostic tool for hypocorticalism is still controversial for a variety of reasons. Some authors have reported that during a stimulation test salivary cortisol is comparable and, in some cases, may be a more superior indicator than serum cortisol (Vining et al. 1983, Gozansky et al. 2005, Marcus-Perlman et al. 2006, Deutschbein et al. 2009). In contrast, our data provide evidence that serum cortisol is a more sensitive measure than salivary cortisol. Limor et al. (2011) evaluated reliability of salivary cortisol during a $1 \mu \mathrm{g}$ ACTH test. Authors compared total serum cortisol to free serum cortisol and to salivary cortisol. They observed good reliability of salivary cortisol in patients with severe hypocorticalism but poor reliability in patients with borderline levels of serum cortisol after stimulation by ACTH. They concluded that salivary cortisol is not sensitive enough to diagnose partial hypocorticalism.

There are various methodologies available to assess adrenocortical reserve by ACTH test. These tests vary in terms of dosage and method of administration (intravenously or intramuscularly). Doses of $250 \mu \mathrm{g}$ and $1 \mu \mathrm{g}$ of ACTH are most commonly used, although there is no consensus in the literature regarding optimal dose. Some studies have provided evidence that $1 \mu \mathrm{g}$, rather than $250 \mu \mathrm{g}$, may be a superior. The higher dose induces supraphysiological stimulation, and consequently milder forms of hypocorticalism may be missed (Thaler and Blevins 1998, Tordjman et al. 2000). In contrast, other studies have shown that the ACTH test is reliable in both variants; both low $(1 \mu \mathrm{g})$ and high/standard $(250 \mu \mathrm{g})$ dose test (Dorin et al. 2003, Agha et al. 2006). Some authors suggest using doses from $10 \mu \mathrm{g}$ to $25 \mu \mathrm{g}$ of ACTH for the low dose variant of the test (Contreras et al. 2004).

In addition to controversy regarding the optimal ACTH dose, the reference or cut-off value for peak cortisol levels after stimulation, to assess adrenocortical insufficiency, also remains controversial. Some authors have established the cut-off limit of peak serum cortisol after the stimulation to be $500 \mathrm{nmol} / 1$, others recommend $540 \mathrm{nmol} / 1$ and $600 \mathrm{nmol} / 1$ (Lindholm et al. 1978, Hurel et al. 1996, Mehta et al. 2005). Some authors define partial adrenal insufficiency as borderline stimulation, with peak cortisol levels ranging from 510 to $550 \mathrm{nmol} / \mathrm{l}$ (Agha et al. 2006).

Differences in testing protocols create obvious difficulties in establishing a generally accepted level of salivary cortisol, which could be compared to serum cortisol cut-offs. Marcus-Perlman et al. (2006) reported that no hypocortical patients had salivary cortisol over $24.28 \mathrm{nmol} / 1$ at 30 minutes with ACTH testing. The authors found that 26 out of 28 control subjects had salivary cortisol levels over $27.6 \mathrm{nmol} / \mathrm{l}$ after $30 \mathrm{~min}$. Contreras et al. (2004) established a normal response for salivary cortisol as $20 \mathrm{nmol} / \mathrm{l}$ at 30 minute. This value remained the same regardless of the dose $(25$ or $250 \mu \mathrm{g})$ used in the test. Limor et al. (2011) reported mean peak salivary cortisol as $55 \mathrm{nmol} / \mathrm{l}$, with a range of 26.22-105.0 $\mathrm{nmol} / 1$ defined as a normal response to $1 \mu \mathrm{g}$ of ACTH.

In our study, the mean salivary cortisol for reference group was $40 \mathrm{nmol} / 1$ (upper - lower quartile 33-53) and 62 (upper - lower quartile 48-75) at 30 and 60 minute, respectively. The lowest observed peak for salivary cortisol was $33.06 \mathrm{nmo} / 1$ in the reference group (no patients in the reference group had a value below this level). The maximal peak of salivary cortisol was $27.54 \mathrm{nmo} / 1$ in the hypocortical group (no hypocortical patients had a value higher than this level). These findings agree with previously published data (MarcusPerlman et al. 2006).

Measuring salivary cortisol has several methodological limitations (Raff 2009). Salivary cortisol reflects the free fraction of total serum cortisol but may be altered by $11 \beta$-hydroxysteroid dehydrogenase in the parotid gland (Perogamvros et al. 2010a). Perogamvros et al. reported better correlation between salivary cortisone and serum free cortisol levels compared to salivary cortisol and serum free cortisol level.

Contreras et al. (2004) and Marcus-Perlman et al. (2006) previously described that cortisol peaked at $30 \mathrm{~min}$ after administration of a low dose $(1 \mu \mathrm{g})$ of ACTH. In our subjects, stimulated by $250 \mu \mathrm{g}$ of ACTH, both serum and salivary cortisol peaked after $60 \mathrm{~min}$. Also other authors observed delayed maximal cortisol peak when a standard high dose of ACTH $(250 \mu \mathrm{g})$ was given (Deutschbein et al. 2009). The prolonged stimulation and half-life of plasma cortisol may explain the difference in results. Daidoh et al. (1995) has previously shown a time dependent response for maximal peak cortisol values depending on the ACTH dose. 


\section{Limitations}

A variety of factors may influence the accuracy of measuring cortisol levels in saliva. Hansen et al. (2008) reported altered levels of salivary cortisol in various material used in the swab chewed by patients. Cotton swabs showed significantly lower levels of cortisol than polyester swabs (reported difference was $62 \%$ ). Therefore, a simple drooling protocol was used to collect samples from study subjects.

Liquid chromatography tandem mass spectrometry (LCGMS) has previously been established as the "gold standard" methodology for measuring salivary cortisol as it eliminates cross reactivity (Perogamvros et al. 2010b, Deutschbein and Petersenn 2013). However, due to fiscal constraints and ease of methodology, we used a commercially available ELISA assay to measure salivary cortisol. With this method each laboratory establishes reference values for the imunoanalytical method (Inder et al. 2012).

\section{Comparison of the reliability saliva vs. serum cortisol}

Deutschbein et al. (2009) compared sensitivity and specificity of salivary and serum cortisol in ACTH and ITT tests in patients suspected of secondary adrenocortical insufficiency. Sensitivity for serum cortisol was $67-79 \%$ and specificity was $71-88 \%$, compared with $63-72 \%$ sensitivity and $72-86 \%$ specificity for salivary cortisol. Gozansky et al. (2005) reported an exponential relationship between salivary cortisol and serum total cortisol with stimulation of the HPA axis by CRH and exercise. The authors found a significantly larger relative change in salivary cortisol compared to serum cortisol in dynamic HPA axis testing. They concluded that salivary cortisol was a more accurate measure than serum cortisol in stimulation tests. We are unable to confirm their conclusions with our findings, as we had significantly higher variability for serum cortisol assessed with ACTH testing $\left(\mathrm{R}^{2}=93.4 \%\right.$ for serum compared to $\mathrm{R}^{2}=89.3 \%$ for saliva, $\mathrm{p}=0.021$ ). The aforementioned difference may be attributed to differences in study design. Gozansky et al. (2005) noted that patients on estrogen therapy were included in these studies. In contrast, we excluded these patients, as well as those suffering from diseases associated with altered CBG levels, from our study.

\section{Conclusions}

In conclusion, our findings provide evidence that there is good correlation between serum and salivary cortisol in ACTH testing. We found slightly, but statistically significantly higher variability of serum cortisol assessment compared to salivary cortisol and so it seems that the serum cortisol is, according to our analysis, statistically more appropriate method of assessing adrenocortical reserve in the ACTH test. This difference is probably of less importance for clinical practice and, undoubtedly, measuring salivary cortisol is advantageous in specific situations of altered CBG level, when the free cortisol fraction needs to be evaluated.

\section{Conflict of Interest}

There is no conflict of interest.

\section{Acknowledgements}

The project was supported by the grant of Czech Ministry of Health NS NT 1127-7 and by the Research project of Charles University (Prvouk, P25/LF1/2).

\section{References}

AGHA A, TOMLINSON JW, CLARK PM, HOLDER G, STEWART PM: The long-term predictive accuracy of the short synacthen (corticotropin) stimulation test for assessment of the hypothalamic-pituitary-adrenal axis. J Clin Endocrinol Metab 91: 43-47, 2006.

ARAFAH BM: Hypothalamic pituitary adrenal function during critical illness: limitations of current assessment method. J Clin Endocrinol Metab 91: 3725-3745, 2006.

ARMITAGE P, BERRY G: Statistical Methods in Medical Research. 3rd ed., Blackwell, London, 1994, p. 131.

CONTRERAS LN, ARREGGER AL, PERSI GC, GONZALEZ NS, CARDOSO EM: A new less-invasive and more informative low-dose ACTH test: salivary steroids in response to intramuscular corticotrophin. Clin Endocrinol (Oxf) 61: 675-682, 2004.

DAIDOH H, MORITA H, MUNE T, MURAYAMA M, HANAFUSA J, NI H, SHIBATA H, YASUDA K: Responses of plasma adrenocortical steroids to low dose ACTH in normal subjects. Clin Endocrinol (Oxf) 43: 311-315, 1995. 
DEUTSCHBEIN T, UNGER N, MANN K, PETERSENN S: Diagnosis of secondary adrenal insufficiency in patients with hypothalamic-pituitary disease: comparison between serum and salivary cortisol during the high-dose short synacthen test. Eur J Endocrinol 160: 9-16, 2009.

DEUTSCHBEIN T, PETERSENN S: Screening for Cushing's syndrome: new immunoassays require adequate normative data. Horm Metab Res 45: 118-123, 2013.

DORIN RI, QUALLS CR, CRAPO LM: Diagnosis of adrenal insufficiency. Ann Intern Med 139: 194-204, 2003.

HAMRAHIAN AH, OSENI TS, ARAFAH BM: Measurements of serum free cortisol in critically ill patients. $N$ Engl $J$ Med 350: 1629-1938, 2004.

GOZANSKY WS, LYNN JS, LAUDENSLAGER ML, KOHRT WM: Salivary cortisol determined by enzyme immunoassay is preferable to serum total cortisol for assessment of dynamic hypothalamic-pituitary-adrenal axis activity. Clin Endocrinol (Oxf) 63: 336-341, 2005.

GRÖSCHL M: Current status of salivary hormone analysis. Clin Chem 54: 1759-1769, 2008.

HANSEN AM, GARDE AH, PERSSON R: Measurement of salivary cortisol-effects of replacing polyester with cotton and switching antibody. Scand J Clin Lab Invest 68: 826-829, 2008.

HUREL SJ, THOMPSON CJ, WATSON MJ, HARRIS MM, BAYLIS PH, KENDALL-TAYLOR P: The short Synacthen and insulin stress tests in the assessment of the hypothalamic-pituitary-adrenal axis. Clin Endocrinol (Oxf) 44: 141-146, 1996.

INDER WJ, DIMESKI G, RUSSELL A: Measurement of salivary cortisol in 2012 - laboratory techniques and clinical indications. Clin Endocrinol (Oxf) 77: 645-651, 2012.

LIMOR R, TORDJMAN K, MARCUS Y, GREENMAN Y, OSHER E, SOFER Y, STERN N: Serum free cortisol as an ancillary tool in the interpretation of the low-dose 1- $\mathrm{gg}$ ACTH test. Clin Endocrinol (Oxf) 75: 294-300, 2011.

LINDHOLM J, KEHLET H, BLICHERT-TOFT M, DINESEN B, RIISHEDE J: Reliability of the 30-minute ACTH test in assessing hypothalamic-pituitary-adrenal function. J Clin Endocrinol Metab 47: 272-274, 1978.

MARCUS-PERLMAN Y, TORDJMAN K, GREENMAN Y, LIMOR R, SHENKERMAN G, OSHER E, STERN N: Low-dose ACTH (1 microg) salivary test: a potential alternative to the classical blood test. Clin Endocrinol (Oxf) 64: 215-218, 2006.

MASSERINI B, MORELLI V, BERGAMASCHI S, ERMETICI F, ELLER-VAINICHER C, BARBIERI AM, MAFFINI MA, SCILLITANI A, AMBROSI B, BECK-PECCOZ P, CHIODINI I: The limited role of midnight salivary cortisol levels in the diagnosis of subclinical hypercortisolism in patients with adrenal incidentaloma. Eur J Endocrinol 160: 87-92, 2009.

MEERAN K, HATTERSLEY A, MOULD G, BLOOM SR: Venepuncture causes rapid rise in plasma ACTH. Br J Clin Pract 47: 246-247, 1993.

MEHTA A, HINDMARSH PC, DATTANI MT: An update on the biochemical diagnosis of congenital ACTH insufficiency. Clin Endocrinol (Oxf) 62: 307-314, 2005.

MELOUN M, HILL M, MILITKY J, KUPKA K: Transformation in the PC-aided biochemical data analysis. Clin Chem Lab Med 38: 553-559, 2000.

MELOUN M, HILL M, MILITKY J, VRBIKOVA J, STANICKA S, SKRHA J: New methodology of influential point detection in regression model building for the prediction of metabolic clearance rate of glucose. Clin Chem Lab Med 42: 311-322, 2004.

PEROGAMVROS I, KEEVIL BG, RAY DW, TRAINER PJ: Salivary cortisone is a potential biomarker for serum free cortisol. J Clin Endocrinol Metab 95: 4951-4958, 2010a.

PEROGAMVROS I, OWEN LJ, KEEVIL BG, BRABANT G, TRAINER PJ: Measurement of salivary cortisol with liquid chromatography-tandem mass spectrometry in patients undergoing dynamic endocrine testing. Clin Endocrinol (Oxf) 72: 17-21, 2010 b.

RAFF H: Utility of salivary cortisol measurements in Cushing's syndrome and adrenal insufficiency. $J$ Clin Endocrinol Metab 94: 3647-3655, 2009.

RIAD-FAHMY D, READ GF, WALKER RF: Salivary steroid assays for screening endocrine function. Postgrad Med $J$ 56 (Suppl 1): 75-78, 1980. 
ŠIMU゚NKOVÁ K, STÁRKA L, HILL M, KŘÍŽ L, HAMPL R, VONDRA K: Comparison of total and salivary cortisol in a low-dose ACTH (Synacthen) test: influence of three-month oral contraceptives administration to healthy women. Physiol Res 57 (Suppl 1): 193-199, 2008.

THALER LM, BLEVINS LS JR: The low dose (1-microg) adrenocorticotropin stimulation test in the evaluation of patients with suspected central adrenal insufficiency. J Clin Endocrinol Metab 83: 2726-2729, 1998.

TORDJMAN K, JAFFE A, TROSTANETSKY Y, GREENMAN Y, LIMOR R, STERN N: Low-dose (1 microgram) adrenocorticotrophin (ACTH) stimulation as a screening test for impaired hypothalamo-pituitary-adrenal axis function: sensitivity, specificity and accuracy in comparison with the high-dose (250 microgram) test. Clin Endocrinol (Oxf) 52: 633-640, 2000.

VINING RF, MCGINLEY RA, MAKSVYTIS JJ, HO KY: Salivary cortisol: a better measure of adrenal cortical function than serum cortisol. Ann Clin Biochem 20: 329-335, 1983. 